This is an author produced version of a paper published in Journal of Clinical Nursing. This paper has been peer-reviewed but does not include the final publisher proof-corrections or journal pagination.

Citation for the published paper:

Carlsson, Anna and Udén, Giggi and Hakansson, Anders and Karlsson, Elisabeth Dejin

"Burn injuries in small children, a population-based study in Sweden."

J Clin Nurs. 2006 Feb;15(2):129-34.

http://dx.doi.org/10.1111/j.1365-2702.2006.01259.x.

Access to the published version may require journal subscription.

Published with permission from: Blackwell Synergy 


\section{Burn injuries in small children, a population-based study in Sweden}

ANNA CARLSSON, MSc, RN

Doctoral student, School of Health and Society, Department of Nursing, Malmö

University, Malmö, Sweden.

GIGGI UDÉN, PhD, RNM, RNT

Professor, School of Health and Society, Department of Nursing, Malmö University,

Malmö, Sweden.

ANDERS HÅKANSSON, PhD, MD

Professor, Department of Community Medicine, Malmö University Hospital, Malmö, Sweden.

ELISABETH DEJIN KARLSSON, PhD, RNM, RNT

Senior Lecturer, School of Health and Society, Department of Nursing, Malmö

University, Malmö, Sweden. 
Number of words: 3479

Journal of Clinical Nursing ISSN 1365-2702

\section{Summary}

* Epidemiological studies of burns in children have mostly been hospital-based and the cases that never reached hospital have been excluded.

* The aim of this study was to describe characteristics of burn injuries in children $(0$ 6 years old), consulting primary care and hospital-based care in Malmö, Sweden.

* Burn-injured children consulting the University Hospital or the 21 Health Centres, during 1998 and 2002 were included.

* The study had a retrospective design with data collected from medical records.

* Chi-squared test was used to analyse differences in nominal data and crosstabulation was used to analyse the proportions between the characteristics of the injuries and sex, age and nationality.

* There were 148 burns, $80 \%$ of which were scalds caused by hot liquid (71\%) or hot food $(29 \%)$.

* The majority of injuries were to boys between one and two years old.

* Children of foreign-born parents were more frequently affected and the extent of the injuries often greater.

* Almost all the accidents (96\%) occurred in the home environment, while a family member was next to the child.

* The Health Centres more often received children affected on hand/arm and by causes such as hot food than the University Hospital.

* Our data demonstrate the importance of developing a programme for the prevention of paediatric scalds with education of family members to be aware of the danger.

Key words: burns; children; prevention and scalds

Correspondence to: Anna Carlsson, School of Health and Society, Department of Nursing, Malmö

University, SE-20506 Malmö, Sweden (tel.: +46 4066579 39; fax: +46 4066581 00;

e-mail: anna.carlsson@hs.mah.se). 


\section{Introduction}

Sweden has the lowest accident mortality in children in the world (SOU 2002:99; IRTAD, 2003). The mortality rate for accidents in Sweden in 1999 was 22/100 000 children (WHO, 2003).

Children get hurt by accidents, mostly in their homes, in the age range 0-4 years (March \& Kendrick, 2000; den Hertog et al., 2000; Mukerji et al., 2000). The most common injuries leading to consultation of hospitals or primary care units are commotio, fractures, luxations, distortions and ruptures of muscles, all of them connected with fall accidents. Other accidents course drowning, poisoning, suffocation and burn injuries (March \& Kendrick, 2000).

Burn injuries are often a serious tragedy for both parents and children caused by the pain and the trauma of dressings, procedures, hospitalisation and emotional adjustments in an immature child, the mortality risk, the long-term rehabilitation and the cosmetic disfigurement (Andersson, 1996; Muerji et al., 2001).

In Copenhagen, Denmark, epidemiological analyses of burn injuries have been carried out every tenth year. The majority of accidents occurred in the home, younger children were at risk, and scalding was the most common type of injury often caused by water from toppled electrical kettles (Sheller \& Thuesen, 1998). Also, a one-year study of burn victims in four counties south-east England revealed that children under the age of five had the highest rate of admission to hospital. The admission from the district health authorities to hospital burn units was 14/100 000 population per year (Wilkinson, 1998). The incidence of burns in the Netherlands was 210/100 000, in 0-4-year-old children, and $65 \%$ of them were scalds. Among the children aged less than four, $80 \%$ of all scald injuries were caused by pushing down or dropping a hot liquid (den Hertog et al., 2000). In a French study, the typical burn-injury patient was a boy with a mean age 
of 4 years, who suffered a scald in the kitchen, and the burn injuries covered less than $10 \%$ of the body surface (Mercier \& Blond, 1996). In Canada, $67 \%$ of burns in children under five were caused by food preparation and consumption, $14 \%$ were bathtub scalds and $19 \%$ were due to flames. Of children under two years of age, $70 \%$ were affected (Ray, 1995).

In Malmö, Sweden, a 6-year prospective study of scald-injured children (0-6 years old), treated at the inpatient burn unit at the University Hospital (UMAS), ran 19901996. Scalding was the cause of $87 \%$ of the burn injured children (Freccero et al., 2000).

Many studies have estimated the epidemiology of paediatric burns but they have often yielded different results depending on the regions where the studies were conducted (WHO, 2004; den Hertog et al., 2000; Sheller \& Thuesen, 1998; Mercier \& Blond, 1996; Ray, 1995). Also, epidemiological studies of burns in children have mostly been hospital-based and the cases that never reached the hospital were excluded. It is important to prevent as many burns as possible and to achieve this it is necessary to be aware of the characteristics of both minor and severe burn injuries in children.

The aim of this study is to describe characteristics in burn injuries in children (0-6 years old), consulting primary care or hospital-based care in Malmö.

\section{Material and Methods}

\section{STUDY AREA AND POPULATION}

This study was performed in Malmö, a city with 257574 inhabitants (2000), in Sweden during 1998 and 2002. There were 21 Health Centres and one University Hospital in Malmö. Among other specialities, the hospital also had a department for burn injuries 
with plastic surgery. Parents of children with burn injuries could voluntarily choose to consult either the emergency unit at the hospital or the Health Centre in their neighbourhood (includes a doctor-on-duty centre).

\section{DATA COLLECTING}

The data was collected from medical records, in a retrospectively designed study. All emergency incoming patients at the University Hospital were recorded, according to age, sex and diagnosis. Approximately 10000 incoming patients per year were registered. All the burn injuries in children found in these registers in both 1998 and 2002 were compiled through medical records, by one of the authors (AC). The internal dropout was due to the fact that not all of the questions could be answered through the medical records.

Children admitted during the study period with any type of burn-related injury were selected for review. Data on the burn-injured children consulting the Health Centres were collected through the diagnosis registration.

Patients who consulted the University Hospital and the Health Centres in Malmö are coded in accordance with the International Classification of Diseases, 9th revision (ICD-9, 1990). All medical records of the children were registered for sex, age and nationality of the parents.

\section{DEFINITIONS}

The nationality of the parents was defined as Swedish-born when at least one of the parents was born in Sweden and as foreign-born when both parents were born in any country outside Sweden (Landstingsförbundet, 2002). Body site, extent and depth of injuries but also causes and location of injuries were investigated. The extent of the 
injuries was classified in two groups: $<2 \%$ and $>2 \%$ (den Hertog et al., 2000). The depth of the injuries was categorised in three degrees: degree 1 was redness in the skin, but intact, degree 2 was blisters and degree 3 was when parts of the skin need to be taken away for recovering (Freccero et al., 2000).

\section{STATISTICAL ANALYSIS}

To analyse differences in nominal data, chi-squared test was used and a difference was considered statistically significant if p? 0.05. The cross tables was used to analyse the proportions between sex, age, nationality and injuries. The statistical analyses were performed using the SPSS program for Windows 11.0 (Norusis, 2002).

The study was approved by the Ethics Committee of Lund University (LU 37-99).

\section{Results}

During the study period 1998 and 2002, 148 children were treated for burn injuries. Children aged $1-2$ years suffered most frequently $(\mathrm{p}=0.0001)$. Boys were represented to the largest extent with $64 \%$ and girls with $36 \%(\mathrm{p}=0.001)$. Table 1 shows the distribution of children according to their sex and age.

Children aged 0-2 years suffered from injuries on the hand, arm, foot or leg to a significantly higher level $(\mathrm{p}=0.04)$. Children with foreign-born parents suffered more often from burn injuries than children with Swedish-born parents $(\mathrm{p}=0.001)$. Children with foreign-born parents also had a larger extent of injury more often than children with Swedish parents $(\mathrm{p}=0.04)$ (Table 2).

Burns were primarily scalds $81 \%(\mathrm{n}=95)(\mathrm{p}=0.001)$. The non-scald burns were caused by a hand on a stove, a foot in a hot candle-wax, a hand on a lamp or by sitting down on a barbeque grill. 
The scalds were mostly caused by hot liquid $71 \%(\mathrm{n}=67)(\mathrm{p}=0.001)$. Scalds by hot food caused the injuries in $29 \%$ of cases $(n=28)$. Accident scenarios in which the child pulled hot food or hot liquid off the stove frequently involved the child trying to climb up and/or reach a pan on the stove or the worktop. The extent of injury was largest to the children injured by hot liquid $(\mathrm{p}=0.01)$. The scalds happened mostly in home environment $(95 \%),(\mathrm{p}=0.001)$ when a family member was present. The depth of injury was often greater in the accidents that occurred outside the home ( $\mathrm{p}=0.01)$ (Table 2).

The distribution between the children consulting the Health Centres, 49\% ( $n=73)$, and the University Hospital, 51\% ( $\mathrm{n}=75)$, differed according to causes of accidents. The University Hospital received more children with other causes of injuries than hot liquid/hot food $(\mathrm{p}=0.04)$ and the site of injury was more often the face $(\mathrm{p}=0.001)$ or the leg/foot $(\mathrm{p}=0.001)$ or with several sites involved $(\mathrm{p}=0.001)$. Those children also suffered more often from injuries of a greater extent $(\mathrm{p}=0.001)$ and depth $(\mathrm{p}=0.05)$. The Health Centres more often received children affected by hot food than the University Hospital $(\mathrm{p}=0.03)$. Arms and hands were more involved in the injuries consulting the Health Centres $(\mathrm{p}=0.03)($ Table 3).

\section{Discussion}

In this study $72 \%(n=106)$ of the burn-injured children were under 3 years old. This age group is also seen as the most common age group for burn injuries in other studies (Sheller \& Thuesen, 1998; den Hertog, 2000; Wilkinson, 1998). Children aged under 3 often stay near their parents while they are cooking and therefore they are more exposed to burn risks. Almost all of the children (96\%) in the present study had their parent close by when the accident occurred. Many of those accidents could have been avoided as they were caused by preventable events such as when the handle of a pan was reachable 
from the cooker front or overheated liquids were handled when the children were nearby.

According to earlier study and as shown in the present study, there seems to be a peak in the affected child between 1 and 2 years old, and at that age close observation of the child is a main rule. Education about preventive precautions can be added to observations, starting at around 2 years old. When children ask questions it offers opportunities for teaching about risks in daily life. From about 3 years children understand the concept of danger (Mercier \& Blond, 1996).

As in other studies (den Hertog, 2000; Mercier \& Blond, 1996) boys were more frequently affected by burn injuries than girls.

The frequency of burn injuries, in particular scalds with a larger extent, was higher among children whose both parents were born abroad than for children of parents of Swedish origin. These findings are supported by studies in the Netherlands (den Hertog, 2000). It is not yet known whether this is due to possible differences in cultural background or economic position. Interesting future research can be directed to the more general question of how a lower social economic position, problems in reading and understanding instructions in another language, a limited living situation, unemployment and distinctive cultural traditions influence the risk of accidents among children.

Previous studies have shown that burn injuries in children are most frequently scalds caused by hot liquid, especially hot coffee or tea (den Hertog et al., 2000; Sheller $\&$ Thuesen, 1998). The present study showed the same causes, although freque ntly caused by hot food (29\%). Burns caused by hot food were more frequent among the children consulting the Health Centres; these burn injuries are seldom described in the literature and may be the reason for the higher extent of hot food causes in the present 
study. Other studies have shown that hot baths were the most frequently observed causes of scalds (Fukunishi et al., 2000; Mercier \& Blond, 1996; Ray, 1995). None of the 148 children in the present study had a scald caused by hot bath water. A major reason may be the regulation of water temperature in taps, to 55 degrees centigrade, according to Swedish law. The limit of 55 degrees is set due to the risk of infection from legionnaires disease.

Most of the injuries were defined as degree 1+2 (redness and blisters) and none of the injuries had a fatal outcome. Many other studies show that the fatal incidence of injuries is often caused by flames or hot tap water (den Hertog, 2000; Fukinishi et al., 2000). Those causes have not been seen in the present study.

During the study period of 1998 and 2002, 148 children were treated for burn injuries. In Malmö, the total numbers of reported accidents in children (0-6 years old) in 1998 and 2002 were 1300 and 1478 respectively $(n=2778)$. About $30 \%$ of the patients consulted the Health Centres and 70\% consulted the University Hospital. Eighty-five percent $(n=1653)$ of the children consulting the University Hospital for accidents in the home environment, had parents of foreign origin. Scald injuries were not separated from other accidents in the injury registrations nor in the registrations for Malmö or for Sweden as a whole (Dept. of Social Medicine, 2004).

It is a long-term process to prevent child accidents. This long-term process cooperates to motivate the parents to take precautions to prevent accidents (McClure \& Douglas, 1996; Arborelius, 1993). The responsibilities of the landlords, concerning the environmental risks in flats, are well regulated in Sweden but not always so well known by the citizens. Campaigns aimed to educate the public about environmental risks in children can be advertised on the airwave media, on billboard posters, at nursery schools and in the Child Health Services. 
Some of the results in the present study are reduced in internal validity due to the internal dropout values between $8 \%$ and $29 \%$ (Rothman \& Greenland, 1998). A negative effect of conducting a record study is the limitations in answering all questions, due to the documentation.

A strength of this study is that it aimed to find all children with burn injuries consulting medical care in Malmö and carefully went through the 20000 diagnoses at the emergency unit at the University Hospital and all diagnoses in the registration at the Health Centres during 1998 and 2002. The children not reached in the present study were those with burn injuries not consulting medical care.

\section{Conclusions}

From the investigation of burn injuries in children aged less than 7 years consulting the University Hospital and the Health Centres in Malmö during 1998 and 2002, the following results were obtained:

* $\quad$ Burn injuries were primarily scalds

* The scalds were caused by hot liquid in $71 \%$ and by hot food in $29 \%$ of cases

* Children aged 1-2 years suffered most frequently and the sites of injuries were more often on the hand, arm, foot or leg

* $\quad$ More boys than girls suffered from burn injuries

* Most of the burn accidents occurred in the home environment when the parent was close by

* Children of foreign-born parents had burn injuries more frequently than children of Swedish-born parents and they also more often had injuries on the hands, arms, leg or feet and injuries of larger extent 
* The Health Centres more often received children affected on the hand/arm and the causes were more often hot food 


\section{Acknowledgement}

This study has been supported by the Primary Health Care Research Department in Scania (Primärvården Skåne, FoUU). 


\section{References}

Andersson, I. (1996) Fakta om skador bland barn och ungdom. (Facts about injuries among children and youth). Stockholm: Barnombudsmannen, 1. (In Swedish)

Arborelius, E. (1993) Teori och praktik om att påverka människors levnadsvanor. (Theory and practice to affect patients' lifestyles) Stockholm: Allmänmedicinskt utvecklingscentrum. (In Swedish).

den Hertog, P C, Blankendaal, F, Ten Hag, S M. (2000) Burn injuries in the Netherlands. Accident Analysis and Prevention, 32, p. 355-364.

Department of Social Medicine. (2004) Skaderegistrering i Region Skåne. (Injury registration in Region Scania). University Hospital UMAS, in Malmö. (In Swedish).

Freccero, C, Svensson, H, Kalhor, S, Larsson, A. (2000) Scalding injuries in immigrant families. Scand. J. of Plastic and Reconstruc. Surg. and Hand Surg. 34 (4). P. 309 13.

Fukunishi, K, Takahashi, H, Kitagishi, H, Matsushima, T, Kanai, T, Ohsawa, H, Sakata, I. (2000) Epidemiology of childhood burns in the Critical Care Medical Center of Kinki University Hospital in Osaka, Japan. Burns 26, p. 465-469. ICD-9 (1990) International Classification of Diseases, 9th Revision, Clinical

Modification. 3rd ed. Washington, DC: Health Care Financing Administration.

IRTAD, OECD-International Road Traffic and Accident Database, www.bast.de/htdocs/fachthemen/irtad/, 20030825.

Landstingsförbundet. (2002) Statistisk årsbok. (The Federation of Swedish County Councils). Stockholm: Landstingsförbundet. (In Swedish)

March, P, Kendrick, D. (2000) Near miss and minor injury information - can it be used to plan and evaluate injury prevention programmes? Accident Analysis and 
Prevention 32, p. 345-354.

McClure, R, Douglas, R M. (1996) The public health impact of minor injury. Accident Analysis and Prevention 28, (4), p. 443-451.

Mercier, C. \& Blond, M H. (1996) Epidemiological survey of childhood burn injuries in France. Burns 22, p.29-34.

Mukerji, G, Chaminia, S, Patidar, G P, Gupta, S. (2000) Epidemiology of paediatric burns in Indore, India. Elsevier Science, India.

Mukerji, G, Shobha, C, Patidar, G H, Suurabh, G. (2001) Epidemiology of paediatric burns in Indore, India. Burns 27, p. 33-38.

Norusis, M. (2002) The SPSS 11.0 guide to data analysis. Upper Saddle River, N.J.: Prentice Hall.

Ray, J G. (1995) Burns in young children: a study of mechanism of burns in children aged 5 years and under in the Hamilton, Ontario Burn Unit. Burns 21, p. 463-466.

Rothman, K J. \& Greenland, S. (1998) Modern Epidemiology. Second edition.

Philadelphia: Lippincott-Raven Publishers, p. 119.

Sheller, J L P. \& Thuesen, B. (1998) Scalds in children caused by water from electrical kettles: effect of prevention through information. Burns 24, p. 420-424.

SOU 2002:99 Statens offentliga utredningar. (State Public Inquiries). Barns skador $i$ Sverige. (Children's injuries in Sweden). Barnsäkerhetsdelegationen, Stockholm 2002. (In Swedish).

World Health Organization (WHO).

http://www3.who.int/whosis/mort/table1_process.cfm , 20030911

World Health Organization (WHO). http://www.who.int/ceh/risks/cehinjuries2/en/ , 20040705

Wilkinson, E. (1998) The epidemiology of burns in secondary care, in a population of 
2.6 million people. Burns, 24, p. 139-143. 
Table 1 Distribution of children according to age and sex (number, percentage and p values).

\begin{tabular}{|c|c|c|c|c|c|c|c|c|c|}
\hline \multicolumn{4}{|c|}{ Boys } & \multicolumn{3}{|c|}{ Girls } & \multicolumn{3}{|c|}{ Total } \\
\hline Age & $\mathrm{N}$ & $\%$ & $\mathrm{p}$ value & $\mathrm{N}$ & $\%$ & $\mathrm{p}$ value & $\mathrm{N}$ & $\%$ & p value \\
\hline$? 1$ & 18 & & NS & 11 & & NS & 29 & 20 & NS \\
\hline $1-2$ & 50 & & NS & 27 & & NS & 77 & 52 & 0.0001 \\
\hline $3-4$ & 19 & & NS & 10 & & NS & 29 & 20 & NS \\
\hline $5-6$ & 8 & & NS & 5 & & NS & 13 & 8 & NS \\
\hline Total & 95 & 64 & 0.001 & 53 & 36 & & 14 & 100 & NS \\
\hline
\end{tabular}

$\mathrm{NS}=$ non significant 
Table 2 Differences regarding burn injuries in small children (N=148).

\begin{tabular}{|c|c|c|c|c|c|c|c|}
\hline \multirow[b]{3}{*}{ Variable } & \multirow[b]{3}{*}{$\%$} & \multicolumn{6}{|c|}{ Dimensions of injuries } \\
\hline & & \multicolumn{2}{|c|}{ Extent of injury 1} & \multicolumn{2}{|c|}{ Site of injury ${ }^{2}$} & \multicolumn{2}{|c|}{ Depth of injury ${ }^{3}$} \\
\hline & & $\%$ & $\mathrm{p}$ value & $\%$ & $\mathrm{p}$ value & $\%$ & $\mathrm{p}$ value \\
\hline \multicolumn{8}{|l|}{ Age } \\
\hline $3-6 y$ & 28 & 42 & & 80 & & 11 & \\
\hline $0-2 y$ & 72 & 58 & NS & 88 & 0.04 & 6 & NS \\
\hline \multicolumn{8}{|l|}{ Sex } \\
\hline Girls & 36 & 53 & & 78 & & 9 & \\
\hline Boys & 64 & 54 & NS & 90 & NS & 6 & NS \\
\hline \multicolumn{8}{|l|}{ Parents' origin } \\
\hline Swedish-born & 44 & 44 & & 76 & & 7 & \\
\hline Foreign-born & 57 & 63 & 0.04 & 92 & 0.04 & 7 & NS \\
\hline \multicolumn{8}{|l|}{ Cause of injury } \\
\hline Hot food & 29 & 36 & & 100 & & 7 & \\
\hline Hot liquid & 71 & 67 & 0.01 & 93 & NS & 6 & NS \\
\hline \multicolumn{8}{|l|}{ Location } \\
\hline Home & 95 & 52 & & 96 & & 6 & \\
\hline Outside & 5 & 80 & NS & 100 & NS & 33 & 0.01 \\
\hline \multicolumn{8}{|l|}{$1=2 \%$} \\
\hline \multicolumn{8}{|c|}{${ }^{2}$ Hand, arm, foot and leg } \\
\hline${ }^{3}$ Degree 3 & & & & & & & \\
\hline
\end{tabular}


Table 3 Distribution of children according to place of consultation and occurrence of injuries, in percent $(\mathrm{N}=136)$.

\begin{tabular}{l}
\hline Consultation \\
Occurrence of injuries \\
\cline { 2 - 3 } \\
\cline { 2 - 3 }
\end{tabular}

\section{Cause of accident}

Hot liquid

Hot food

Other
64

41

71

\section{Site of injury}

$\begin{array}{lccc}\text { Face } & 17 & 83 & 0.001 \\ \text { Trunk } & 42 & 58 & \text { NS } \\ \text { Arm/hand } & 61 & 39 & 0.03 \\ \text { Leg/foot } & 21 & 79 & 0.001 \\ >3 \text { of above } & 0 & 100 & 0.001\end{array}$

\section{Extent of injury}
A) $<2 \%$
75
25
NS
B) $=2 \%$
41
59
0.001

\section{Depth of injury}

Degree 1+2

Degree 3
55

22
45

78
NS

0.05

Total

51

49

1) D. on dc.=Doctor-on-duty centre. 